\title{
Algumas considerações sobre leituras estativas de verbos de movimento em Português Europeu
}

\author{
Luís Filipe Cunha, António Leal \& Fátima Silva \\ Universidade do Porto, CLUP
}

\begin{abstract}
:
A significant number of the so-called verbs of motion exhibit a consistent alternation between an eventive and a stative reading. In this view, the main goal of this paper is to investigate the linguistic factors that contribute to this aspectual behaviour regarding verbs of motion in European Portuguese. In particular, we consider the fictive motion hypothesis; the influence of tenses like the Presente do Indicativo (Simple Present) and the Imperfeito (Imperfect) that stativize the predications with which they co-occur; the status of the "figure" and, finally, the role played by the different subclasses of verbs of motion, with special reference to the distinction between inherently directed verbs and manner of motion verbs. We conclude that, like other types of verbs, the aspectual feature of dynamicity seems to play a crucial role in the alternation at hand.
\end{abstract}

Keywords: verbs of motion, eventive/stative alternation, aspectual properties, dynamicity

Palavras-chave: verbos de movimento, alternância evento/estado, propriedades aspetuais, dinamicidade

\section{Introdução}

Os designados verbos de movimento, i.e., verbos que, de alguma forma, exprimem deslocação em termos espaciais, têm despertado o interesse de vários linguistas, que têm procurado analisar o seu comportamento e descrever as suas propriedades definitórias sob diferentes pontos de vista (cf. e.g. Jackendoff, 1990; Levin, 1993; Talmy, 1996; 2000).

Uma das questões mais desafiantes que estes verbos nos colocam prende-se com as propriedades aspetuais das predicações em que intervêm. Na realidade, e como já foi apontado por diversos autores (cf. e.g. Matsumoto, 1996; Iwata, 1996; Gawron, 2007; 2009; Morimoto, 2013; 2018 e, especificamente para o Português, Leal, Cunha \& Silva, 2018 e Cunha, Leal \& Silva, 2018), certos verbos de movimento admitem uma alternância entre leituras eventivas e estativas, tal como ilustrado nos exemplos (1) e (2).

(1) O barco atravessou o rio Douro. (leitura eventiva)

(2) A Ponte da Arrábida atravessa o rio Douro. (leitura estativa)

No entanto, é importante notar que nem todos os verbos de movimento revelam a capacidade de participar em alternâncias deste género. Assim, por exemplo, um verbo como "rebolar" apenas parece poder surgir em configurações eventivas, não se mostrando compatível com leituras de cariz estativo, como o contraste que se segue comprova:

(3) A bola rebolou de uma ponta à outra do campo. (leitura eventiva)

(4) * As dunas rebolam pela praia. (leitura estativa)

Os objetivos centrais deste trabalho são, pois, por um lado, contribuir para o esclarecimento da questão de que verbos de movimento permitem a alternância entre leituras estativas e eventivas e, por outro, procurar explicitar quais os fatores linguísticos que estão subjacentes a uma tal variação em termos aspetuais. Deste 
modo, principiaremos por descrever a alternância em questão e, num segundo momento, discutiremos algumas propostas de explicação para a sua ocorrência, dando particular atenção à relevância das classes de verbos de movimento no licenciamento das leituras estativas das predicações.

\section{A distinção aspetual entre estados e eventos com verbos de movimento}

A distinção aspetual entre estados e eventos é sobejamente conhecida na literatura sobre Aspeto (cf., entre muitos outros, Vendler, 1967; Dowty, 1979; Mourelatos, 1981; Moens, 1987; Binnick, 1991; Kamp \& Reyle, 1993, Smith, 1991/1997), pelo que aqui nos limitaremos a abordar apenas algumas das questões que nos parecem mais relevantes para a discussão que seguidamente levaremos a cabo.

Os estados podem ser descritos como situações tendencialmente estáveis que se caracterizam pelo não dinamismo e pela plena homogeneidade, i.e., obedecem estritamente à designada propriedade de subintervalo, que, de uma forma muito sucinta, postula que qualquer parte de uma eventualidade é exatamente idêntica ao seu todo.

Contrariamente aos estados, os eventos são situações dinâmicas, i.e., são constituídas por uma ou mais (sub)fases sucessivas, que diferem por vezes na sua natureza (e.g., fases processuais vs fases culminativas), conceptualmente identificáveis e atómicas.

Assim, se um qualquer subintervalo em que é verdade que "O João é alto" descreve adequadamente uma situação de "O João ser alto", o mesmo não se passa, por exemplo, com uma eventualidade do tipo de "A Maria nadar": existem subfases mínimas (e.g. as braçadas) que não podem ser subdivididas em intervalos menores em que a situação de "A Maria nadar" se verifica.

Esta distinção reflete-se num conjunto de critérios linguísticos (cf. Dowty, 1979; Smith, 1991/1997; Cunha, 2004) de que é exemplo a (in)compatibilidade com certos verbos de operação aspetual. Nessa medida, os estados são incompatíveis com operadores como "começar a" ou "parar de", enquanto os eventos aceitam a sua presença, como as frases de (5) a (8) comprovam.

(5) * O João começou a ser alto. (estado)

(6) * A Maria parou de ter olhos azuis. (estado)

(7) O João começou a gritar. (evento)

(8) A Maria parou de escrever a tese. (evento)

Este tipo de distinção estende-se aos designados verbos de movimento, que, em contextos adequados, tanto podem surgir com leituras eventivas (cf. (9)) como com interpretações estativas (cf. (10)).

(9) Só três ciclistas atravessaram ontem o posto fronteiriço de Roszke... (par=ext ${ }^{1} 220409$-pol-93a-2)

(10) Rumo ao Fundão, a estrada atravessa um magnífico planalto. (par=ext136850-des-95b-2: 9)

Como se pode observar nos exemplos (11) a (14), os testes propostos para a identificação da estatividade permitem distinguir estes dois tipos de construção:

(11) O João começou a subir o monte. (evento)

(12) * A estrada começou a subir o monte. (estado)

(13) A Maria parou de correr. (evento)

(14) * A linha de comboio parou de correr ao longo da margem do Douro. (estado) ${ }^{2}$

\footnotetext{
${ }^{1}$ Os exemplos identificados com "par=ext" são retirados do corpus CETEMPúblico.
} 
No entanto, e como já referimos brevemente na introdução, nem todos os verbos de movimento participam na alternância entre interpretações eventivas e estativas. Por outras palavras, e como veremos ao longo do presente trabalho, existem verbos de movimento que se compatibilizam com ambas as leituras, outros que somente ocorrem em predicações que descrevem eventos e há ainda alguns verbos locativos que apenas admitem leituras de estado.

Importa, por conseguinte, tentar compreender que fatores condicionam as diferentes possibilidades, em termos de expressão do aspeto, que estão disponíveis para os verbos de movimento. É a esta questão que dedicaremos as próximas secções deste artigo.

\section{Fatores subjacentes à distinção aspetual entre leituras eventivas e estativas com verbos de movimento}

A questão da determinação dos fatores subjacentes à alternância entre leituras estativas e leituras eventivas com verbos de movimento em português europeu foi anteriormente abordada em Leal, Cunha \& Silva (2018) e Cunha, Leal \& Silva (2018). Nestes trabalhos foram analisadas várias hipóteses de tratamento para a referida alternância aspetual, que passamos a rever.

\section{A hipótese do movimento fictício (Talmy, 2000)}

Uma primeira hipótese tida em conta passou por considerar que a interpretação estativa atribuída aos verbos de movimento seria uma manifestação de "movimento fictício"3 ("fictive motion", na terminologia de Talmy, 2000).

Segundo o autor, este movimento caracteriza-se pela apresentação de um referente de natureza estática como algo que se move ou que, de alguma forma, se desloca num percurso. Trata-se, pois, de um movimento ficcionalmente construído.

No entanto, considerar que o "movimento fictício" é o principal responsável pela possibilidade de alternância entre leituras estativas e eventivas associadas aos verbos de movimento afigura-se bastante problemático. Na realidade, existem muitos casos que podem ser considerados de "movimento fictício" e que mantêm propriedades eventivas bem evidentes (cf. (15)):

(15) Durante duas horas, árvores e arbustos desfilaram ao longo da estrada.

Nesse sentido, parece ser possível concluir que, embora todos os casos de leituras estativas com verbos de movimento possam ser considerados, em certa medida, como expressão de "movimento fictício", nem todas as manifestações de "movimento fictício" dão necessariamente origem a interpretações estativas das predicações a que se aplicam. Por essa razão, as leituras estativas de verbos de movimento não poderão ser simplesmente explicadas como o resultado da interpretação como "movimento fictício", na medida em que este conceito abarca igualmente configurações de natureza marcadamente eventiva.

\footnotetext{
${ }^{2}$ Sublinhe-se que, embora só tenhamos considerado, no presente trabalho, as alternâncias relativas ao comportamento face a certos operadores aspetuais, a distinção entre leituras estativas e eventivas com verbos de movimento responde satisfatória e consistentemente aos diferentes testes propostos na literatura para a distinção entre estados e eventos. Para uma análise mais aprofundada desta questão, veja-se Leal, Cunha \& Silva, 2018.

${ }^{3}$ Há outros termos usados na literatura que são entendidos como equivalentes (total ou parcialmente) aos termos propostos por Talmy: "subjective motion" em Langacker (1986) e Matsumoto (1996); "non-actual motion” em Blomberg \& Zlatev (2014), entre outros.
} 


\section{A hipótese da relevância dos tempos gramaticais}

Uma segunda hipótese considerada em Leal, Cunha \& Silva (2018) e Cunha, Leal \& Silva (2018) prende-se com a relação entre a possibilidade de obtenção de leituras estativas com verbos de movimento e os tempos gramaticais que ocorrem na predicação. Sob este ponto de vista, as leituras estativas de verbos de movimento seriam essencialmente desencadeadas pelas propriedades estativizadoras do Presente do Indicativo e do Pretérito Imperfeito (por comodidade, doravante designado simplesmente como Imperfeito), que tipicamente estativizam as situações com que se combinam (cf. Kamp \& Rohrer, 1983; Kamp \& Reyle, 1993; Oliveira \& Lopes, 1995; Cunha, 2004).

Se, no entanto, procedermos a uma observação mais atenta de diversos exemplos relevantes, seremos forçados a reconhecer que existem algumas questões inultrapassáveis que põem em causa a adequação de uma hipótese deste género.

$\mathrm{Na}$ verdade, a comparência de tempos gramaticais como o Presente ou o Imperfeito não pode ser considerada uma condição necessária nem suficiente para a obtenção de interpretações estativas de verbos de movimento. Ao contrário do que seria de esperar no referido contexto, a oposição entre estados e eventos com verbos de movimento parece persistir: há casos em que se observa uma interpretação semelhante à dos estados básicos, em que o Presente e o Imperfeito se limitam a localizar temporalmente as situações com que coocorrem, como sucede em frases como (16) e (18); há também, em contrapartida, configurações em que surgem leituras semelhantes às dos estados derivados a partir de eventos, i.e., em que o Presente e o Imperfeito induzem alterações ao nível do perfil aspetual da predicação, em particular no que se refere à atribuição de uma interpretação de habitualidade (cf. (17) e (19)).

(16) A A1 vai do Porto até Lisboa. (leitura de presente real)

(17) O Alfa vai do Porto até Lisboa. (leitura habitual)

(18) As vias romanas atravessavam a Península Ibérica. (leitura de mera localização temporal)

(19) Os dinossáurios atravessavam a Península Ibérica. (leitura habitual)

Por outro lado, em contextos adequados, mantém-se a interpretação estativa mesmo quando alguns verbos de movimento surgem com outros tempos gramaticais que, por princípio, não induzem estatividade, como sucede com o Pretérito Perfeito Simples (cf. (20)).

(20) As vias romanas atravessaram a Península Ibérica durante séculos.

A partir da breve discussão que acabámos de efetuar, podemos, portanto, concluir que a mera comparência do Presente do Indicativo ou do Imperfeito não é suficiente para justificar a distinção entre leituras estativas e eventivas com verbos de movimento, na medida em que tal oposição permanece perfeitamente visível nestas condições.

Nesse sentido, e embora reconheçamos que os tempos gramaticais influenciam consideravelmente o perfil aspetual das predicações com que se combinam, não podem, no caso em apreço, ser encarados como a principal origem da alternância entre interpretações eventivas e estativas dos verbos de movimento. 


\section{A hipótese do tipo de Sujeito ${ }^{4}$}

Relativamente ao papel desempenhado pelos Sujeitos que denotam a figura que está envolvida no movimento, de acordo com Leal, Cunha \& Silva (2018) e Cunha, Leal \& Silva (2018), as suas propriedades não podem, igualmente, ser tomadas como decisivas, seja a oposição considerada aquela que envolve entidades móveis (cf. (21)-(22)) ou não móveis (cf. (23)-(24)), seja a atribuição de outras características à figura, concebida, por exemplo, como entidade que pode denotar um percurso (cf. (25)) ou um cenário para a deslocação ou não (cf. (26)), porque podemos ter leituras estativas ou eventivas com todos os tipos de Sujeitos.

(21) O rapaz atravessou a montanha. (evento)

(22) O tapete atravessa a sala. (estado)

(23) O túnel atravessa a montanha. (estado)

(24) O túnel atravessou a montanha em 6 meses (evento)

(25) A estrada desce até ao vale. (estado)

(26) As cortinas descem até ao chão. (estado)

Assim, observamos que "o túnel”, uma entidade tipicamente concebida como sendo não móvel, pode integrar tanto configurações estativas como (23) quanto estruturas eventivas como (24); por outro lado, entidades que inequivocamente manifestam mobilidade podem, também elas, surgir tanto em predicações eventivas ("o rapaz", em (21)) como estativas ("o tapete", em (22)). . $^{5}$

Mesmo quando a figura denota um percurso ou um cenário para a deslocação, o facto de representar entidades não móveis ou móveis continua a ser irrelevante, como (25) e (26) confirmam: em ambos os casos temos interpretações inequivocamente estativas, independentemente de o tipo de Sujeito ser móvel ("as cortinas", em (26)) ou não móvel (“a estrada”, em (25)).

Em suma, a alternância entre leituras estativas e eventivas de verbos de movimento não parece estar na dependência da escolha do tipo de Sujeito com papel de figura que ocorre nas predicações em causa, nem, como vimos, dos tempos gramaticais ou da aplicação do "movimento fictício".

$\mathrm{Na}$ sequência das observações referidas anteriormente, é proposto, em Leal, Cunha \& Silva (2018) e Cunha, Leal \& Silva (2018), que os verbos em geral se caracterizam, ao nível lexical, por um traço [ \pm dinâmico], que se prende com o aspeto das predicações. Verbos [+dinâmicos] determinam uma predicação eventiva, enquanto verbos [-dinâmicos] determinam uma predicação estativa. No que concerne especificamente aos verbos de movimento, os autores sugerem que estão incluídos numa classe de verbos que podemos designar por "verbos espaciais" e que podem ser de três tipos: verbos como "situar-se" e "localizarse" são [-dinâmicos], pelo que projetam predicações estativas; verbos como "deslocar-se" e "andar" são

\footnotetext{
${ }^{4}$ Por simplificação, vamos usar o termo "sujeito" nesta subsecção para nos referirmos ao argumento que ocupa a posição sintática de sujeito em frases ativas. Na verdade, só estamos a tratar construções na voz ativa, pelo que não é problemático que esta designação não cubra os casos em que o argumento relevante é realizado como um sintagma-por em passivas sintáticas. Por outro lado, não usamos o termo "argumento externo", na medida em que, no caso de verbos inacusativos, como "chegar", o argumento relevante, que é realizado como sujeito, corresponde, na verdade a um argumento interno.

${ }^{5}$ Tal como um revisor deste trabalho aponta, a questão da "mobilidade" das entidades reveste-se de uma grande complexidade. Na realidade, há que distinguir entre entidades, tipicamente animadas, que manifestam um movimento autónomo (e.g. "rapaz") de entidades, como "tapete", cujo movimento resulta da intervenção de fatores ou de agentes externos. No entanto, e independentemente da causa do movimento, todas estas entidades revelam a propriedade comum de poderem sofrer algum tipo de deslocação em termos espaciais, como os nossos exemplos ilustram. Assim, estamos, neste trabalho, a designar por "móvel" uma entidade que, de acordo com o nosso conhecimento do mundo, é tipicamente percebida como "movível” ("tapetes são movíveis, mas montanhas, tipicamente, não). Uma análise mais aprofundada da relação entre o tipo de entidades e a natureza do movimento a que estão sujeitas está para além dos objetivos do presente trabalho, embora se revele um tema de investigação a considerar no futuro.
} 
[+dinâmicos], pelo que projetam predicações eventivas; verbos como "ir", "subir", "correr”, “escorregar” e "ziguezaguear" são, lexicalmente, não especificados quanto ao traço dinamismo, pelo que podem comparecer em predicações estativas ou eventivas.

Os verbos que são tradicionalmente classificados como "de movimento" entram num dos seguintes grupos, independentemente da subclasse a que pertençam: ou são [+dinâmicos], ou são não especificados quanto ao traço de dinamismo. Isto implica que os verbos de movimento associados ao traço [+dinâmico] projetem predicações que necessariamente são de natureza eventiva. No caso dos verbos de movimento não especificados quanto a este traço dinâmico, serão fatores contextuais (e.g. tipo de Sujeito, tempo gramatical) a favorecer (embora não a determinem) uma leitura estativa ou eventiva da predicação, dando, por isso, origem à alternância em questão. ${ }^{6}$

\section{A hipótese das subclasses de verbos de movimento}

Os trabalhos anteriormente mencionados não consideram, no entanto, todos os fatores possíveis para a origem da alternância entre leituras estativas e eventivas em PE. De facto, uma das hipóteses que não foi explorada em Leal, Cunha \& Silva (2018) ou Cunha, Leal \& Silva (2018) está relacionada com particularidades lexicais dos verbos de movimento. Por outras palavras, levanta-se a questão de saber se, do ponto de vista lexical, podem ser encontradas subclasses de verbos de movimento que sejam sensíveis à alternância estado/evento. Esta é uma ideia que tem sido referida na literatura de índole cognitiva, a propósito da distinção "movimento fictício/ não fictício" ("fictive/non fictive motion"), que abordámos anteriormente. Por exemplo, Matsumoto (1996), a partir de dados do inglês e do japonês, refere que, para que possa haver uma leitura de "movimento fictício", é necessário que a predicação codifique alguma informação relativa ao percurso ("path") - expressa pelo verbo ou por algum sintagma preposicional ou adverbial - e que, caso o verbo seja de modo de movimento, essa informação sobre o modo possa ser relacionada com alguma característica específica do percurso (cf. Rojo \& Valenzuela, 2003 para uma comparação entre o inglês e o espanhol). Matlock (2004) aponta no mesmo sentido, defendendo que, numa construção de "movimento fictício", o significado do verbo contribui para a descrição da configuração da entidade relevante. Isto é particularmente visível, de acordo com a autora, no caso dos verbos de modo de movimento, em que existe uma relação entre a configuração (estática) da entidade relevante (na leitura fíctícia) e a forma como o movimento é realizado ao longo de um percurso ou num determinado espaço (na leitura não fictícia). Por seu lado, Blomberg \& Zlatev_(2014) referem que o inglês é a única língua estudada sistematicamente em que há uma utilização produtiva de verbos de modo de movimento em construções de movimento "não real" ("nonactual motion"). Pelo contrário, línguas como o japonês não permitem esta construção, enquanto o sueco permite, mas de forma bastante limitada.

Para explorarmos esta hipótese, partimos da proposta de Levin (1993), feita para o Inglês, para estabelecermos distinções no interior da classe dos verbos de movimento em Português. Assim, e seguindo a generalidade da literatura, consideramos duas grandes classes de verbos: (i) verbos de movimento inerentemente direcionado (VMID), que procedem à especificação da direção do movimento, mesmo não havendo sintagma direcional explícito (como "go", "arrive", "come", "enter"), e (ii) verbos de modo de

\footnotetext{
${ }^{6}$ Sublinhe-se que a hipótese de análise que aqui defendemos trata a ambivalência em causa como um caso de vagueza ou de subespecificação relativamente ao traço de dinamismo, e não como um caso de ambiguidade ou de homonímia, associando cada verbo a duas entradas lexicais independentes, uma opção bem menos económica e que requereria uma clara motivação para a postulação, em cada caso concreto, de um par de entradas lexicais distintas. Esta segunda opção, já por nós rejeitada em trabalho anterior (cf. Cunha, Silva \& 2017), implicaria sobrecarregar o léxico. Em segundo lugar, para além da alternância aspetual em questão, não existem outras evidências ou justificações semânticas para a duplicação de entradas lexicais. Por fim, esta opção deixaria por justificar um certo paralelismo, em termos de possibilidade de combinação com sintagmas preposicionais, entre as leituras eventiva e estativa, que a maioria destes verbos aparentemente apresenta.
} 
movimento (VMM), que descrevem o movimento que, tipicamente (mas não necessariamente), envolve a deslocação de uma entidade (como "roll" e "run"). ' Vejam-se alguns exemplos destes verbos em (27). Consideramos ainda quatro verbos - "mover-se", "deslocar-se", "circular" e "locomover-se" - que são, de um ponto de vista lexical, relativamente "neutros" no que concerne à distinção "modo de movimento" e "direção inerente", na medida em que nem especificam a direção do movimento, nem descrevem o modo do movimento que lhes está associado.

VMID: ascender, atingir, avançar, baixar, cair, chegar, descer, entrar, fugir, imergir, ir, partir, recuar, regressar, sair, subir, submergir, vir, voltar

VMM: acelerar, andar, cambalear, caminhar, correr, coxear, desfilar, deslizar, galopar, girar, mancar, nadar, passear, pinotear, pular, rastejar, serpentear, voar, ziguezaguear

Para a constituição de um corpus que contemplasse estas subclasses de verbos no Português, recorremos ao CETEMPúblico e procedemos a uma extração das ocorrências de uma lista de verbos dos subtipos considerados - verbos de movimento inerentemente direcionado e verbos de modo de movimento. A busca foi restringida às frases contendo estes verbos no Presente do Indicativo, dado que, tal como vimos anteriormente, este tempo favorece a ocorrência de leituras estativas. Procedemos posteriormente a uma análise dos exemplos, no sentido de determinar quais as leituras - estativa ou eventiva - dos exemplos do corpus e quais os verbos que permitem a leitura estativa. Os resultados gerais são apresentados na tabela 1.

\begin{tabular}{|c|c|c|c|}
\hline \multicolumn{4}{|c|}{ Verbos de movimento } \\
\hline subclasse & n. ${ }^{\circ}$ verbos analisados & $\begin{array}{r}\text { n. }^{\circ} \text { de verbos com } \\
\text { leitura estativa } \\
\text { (para além de } \\
\text { leitura eventiva) }\end{array}$ & $\begin{array}{r}\mathrm{n} .^{\mathrm{o}} \text { de verbos sem } \\
\text { leitura estativa } \\
\text { (apenas com leitura } \\
\text { eventiva) }\end{array}$ \\
\hline VMID & $54(47 \%)$ & 32 & 22 \\
\hline VMM & $57(49,5 \%)$ & 15 & 42 \\
\hline Verbos não especificados & $4(3,5 \%)$ & 0 & 4 \\
\hline totais & $115(100 \%)$ & $47(40,9 \%)$ & $68(59,1 \%)$ \\
\hline
\end{tabular}

Tabela 1: resultados da análise do corpus

Assim, dos 115 verbos analisados, 68 verbos (59,1\%) ocorrem apenas com leituras eventivas enquanto 47 verbos $(40,9 \%)$ ocorrem tanto com leituras eventivas como com leituras estativas (consideramos a existência, neste caso, de pelo menos um exemplo de leitura estativa para englobarmos o verbo em questão neste segundo grupo). Embora o número de verbos que permite ambas as leituras seja menor do que o número daqueles que permitem apenas leituras eventivas, constitui, contudo, um percentual significativo, o que indicia que as leituras estativas não têm um caráter residual. Vejamos agora as tabelas 2 e 3 , com os resultados de cada um dos principais grupos de verbos de movimento.

\footnotetext{
${ }^{7}$ Levin (1993) aponta outras subclasses de verbos de movimento em inglês: verbos de movimento usando um veículo, verbos do tipo "leave", "waltz", "chase" e "accompany". Contudo, estes tipos de verbos não foram considerados no nosso estudo, na medida em que não parecem ser subclasses produtivas em português europeu ou apresentar particularidades morfossintáticas que permitam a sua identificação nesta variedade.
} 


\begin{tabular}{|c|r|r|}
\hline \multicolumn{3}{|c|}{ VMID } \\
\hline n. $^{\circ}$ verbos analisados & $\begin{array}{r}\text { n. }{ }^{\circ} \text { de verbos com } \\
\text { leitura estativa }\end{array}$ & $\begin{array}{r}\text { n. }{ }^{\circ} \text { de verbos sem } \\
\text { leitura estativa }\end{array}$ \\
\hline $54(100 \%)$ & $32(59,3 \%)$ & $22(40,7 \%)$ \\
\hline
\end{tabular}

Tabela 2: VMID

\begin{tabular}{|c|r|r|}
\hline \multicolumn{3}{|c|}{ VMM } \\
\hline n. $^{\circ}$ verbos analisados & $\begin{array}{r}\text { n. }{ }^{\circ} \text { de verbos com } \\
\text { leitura estativa }\end{array}$ & $\begin{array}{r}\text { n. }{ }^{\circ} \text { de verbos sem } \\
\text { leitura estativa }\end{array}$ \\
\hline $57(100 \%)$ & $15(26,3 \%)$ & $42(73,7 \%)$ \\
\hline
\end{tabular}

Tabela 3: VMM

Assim, dos 54 verbos de movimento inerentemente direcionado, 22 (40,7\%) ocorrem no corpus apenas com leitura eventiva, enquanto $32(59,3 \%)$ ocorrem tanto com leitura eventiva como com leitura estativa (pelo menos com uma ocorrência deste tipo de leitura). Quanto aos verbos de modo de movimento, foram pesquisados 57 , tendo a análise mostrado que 42 verbos $(73,7 \%)$ apenas ocorrem com leitura eventiva, enquanto $15(26,3 \%)$ ocorrem tanto com leitura eventiva como com leitura estativa (pelo menos com uma ocorrência deste tipo de leitura). Quanto aos 4 verbos "neutros", ocorrem no corpus apenas com leitura eventiva.

Os resultados apresentados mostram, portanto, que tanto os verbos de movimento inerentemente direcionado (e.g. "entrar") quanto os de modo de movimento (e.g. "correr") podem ocorrer tanto com leituras estativas (cf. (28) e (29)) quanto com leituras eventivas (cf. (30) e (31)), mas também se constata que há uma tendência para a leitura estativa estar associada mais a verbos de movimento inerentemente direcionado do que a verbos de modo de movimento.

(28) As camionetas apenas são autorizadas a descer uma a uma a sinuosa estrada que entra na povoação. (par=ext779413-pol-97b-1)

(29) Abandone o apeadeiro da Lousã e siga em direcção a Cacilhas, por uma estrada que corre ao lado da linha ferroviária. (par=ext5683-nd-91b-1)

(30) Com a curiosidade aguçada, o primeiro de um grupo de jipe [sic] esqueceu o «road-book» e entrou na aldeia. (par=ext270580-des-96a-2)

(31) O esloveno correu então bem junto ao árbitro, enquanto dava beijinhos no emblema da camisola... (par=ext13707-des-98b-2)

Para além disso, dentro de cada grupo de verbos, a percentagem dos verbos que permitem leitura estativa é substancialmente maior no caso dos verbos de movimento inerentemente direcionado (59,3\%) do que no caso dos verbos de modo de movimento $(26,3 \%)$. Esta tendência vai, aparentemente, ao encontro do que é 
dito em Matlock (2004) e Matsumoto (1996) sobre o "movimento fictício" e a relação deste tipo de leitura com as subclasses de verbos. ${ }^{8}$

No entanto, a análise dos dados forneceu resultados cuja explicação levanta problemas. Vejamos quais. Em primeiro lugar, verificou-se que, como é dito na literatura, no interior da subclasse dos VMM existe inequivocamente uma variação ao nível da aceitabilidade das leituras estativas: há verbos que as admitem e outros que não. Por exemplo, "ziguezaguear" e "nadar" são ambos VMM, mas apenas "ziguezaguear" ocorre com leitura estativa (cf. (32)), enquanto "nadar" apenas ocorre com leitura eventiva (cf. (33)).

(32) Numa imagem há uma estrada de terra que ziguezagueia voluptuosamente entre arbustos, paralela ao mar. (par=ext432807-soc-96b-1) (VMM com leitura estativa)

(33) $\mathrm{O}$ que no filme aparece junto foi, de facto, filmado em separado: os bebés nadam numa piscina de Londres, junto de suas mães e em toda a segurança, e o fundo marinho é do Mar Vermelho em Sharm, no Egipto. (par=ext250665-soc-95b-2) (VMM com leitura eventiva)

Quanto aos VMID, esperava-se, de acordo com a literatura, que o número de verbos que não permitem leituras estativas fosse residual. Contudo, verificou-se que 40,7\% não ocorre com leituras estativas, o que não é um número negligenciável. A título exemplificativo, veja-se que "cair" e "retroceder" são ambos VMID, mas, enquanto "cair" ocorre tanto com leitura eventiva como com leitura estativa (cf. (34)), "retroceder" apenas ocorre com leitura eventiva, como em (35).

(34) A janela está escondida por um cortinado comprido que cai junto a uma lareira apagada. (par=ext85438-soc-91b-2) (VMID com leitura estativa)

(35) Pedro Miguel retrocedeu a pé para o automóvel. (par=ext102624-soc-97a-2) (VMID com leitura eventiva)

Em segundo lugar, quando se tem em conta verbos da mesma subclasse que são semanticamente aparentados, surgem novos problemas. Vejamos o caso dos verbos de movimento descendente ("down verbs"; cf. Bosque, 2015). Em Português, verbos como "descer" e "baixar" são verbos de movimento inerentemente direcionado. Para além disso, ambos estão relacionados lexicalmente com a noção de verticalidade e com a de "movimento descendente". Contudo, apesar destas semelhanças, apenas as predicações construídas com o verbo "descer" podem ter leitura estativa (cf. (36)). Pelo contrário, esta leitura está vedada às predicações com "baixar", que apenas exibem leituras eventivas (cf. (37)).

(36) ... damos connosco num poço que desce na vertical. (par=ext174664-clt-93a-2)

(37) *... damos connosco num poço que baixa na vertical.

Uma assimetria deste tipo pode ser também encontrada em outros verbos semanticamente relacionados, como os verbos de modo de movimento "correr" e "andar". Assim, "correr" pode ocorrer em predicações eventivas e estativas (cf. (38)), enquanto "andar" apenas ocorre em predicações com leitura eventiva" (cf. (39)).

\footnotetext{
${ }^{8}$ Dado o grande volume de dados envolvidos, não quantificámos neste trabalho, para cada verbo que admite ambas as possibilidades, qual a percentagem de leituras estativas face à de interpretações eventivas.

${ }^{9}$ Blomberg \& Zlatev (2014) argumentam no mesmo sentido a partir de dados do inglês, referindo que os verbos "run", "dash", "scoot" e "sprint" podem ocorrem em construções de movimento "actual", mas não de movimento "non-actual".
} 
(38) A estrada que corre ao lado da bacia do rio Cávado é uma verdadeira manta de retalhos. (par=ext663060-soc-98a-1)

(39) * A estrada que anda ao lado da bacia do rio Cávado é uma verdadeira manta de retalhos.

Uma explicação para a possibilidade de ocorrência de leituras estativas em predicações com verbos de movimento que se baseie nas diferentes subclasses de verbos dificilmente consegue dar conta das assimetrias que acabamos de apontar. Deste modo, os resultados na nossa análise indicam que a consideração de classes de verbos de movimento não ajuda a explicar a alternância entre leituras estativas e eventivas destes verbos, pois, nas classes propostas, é possível encontrar casos de alternância e casos em que esta não existe. Pelo contrário, a possibilidade de alternância aspetual estado/evento parece depender de propriedades lexicais idiossincráticas dos verbos em questão. Por outras palavras, a possibilidade de projetar predicações estativas ou eventivas parece ser uma propriedade da semântica lexical dos verbos de movimento.

Esta é a proposta que é feita em Leal, Cunha \& Silva (2018) e Cunha, Leal \& Silva (2018). Os autores sugerem que os verbos em geral - e não apenas os verbos de movimento - se caracterizam, ao nível lexical, por um traço [ \pm dinâmico], que se prende com o aspeto das predicações. Verbos [+ dinâmicos] determinam uma predicação eventiva, enquanto verbos [- dinâmicos] determinam uma predicação estativa.

Isto significa que a alternância entre interpretações estativas e eventivas de verbos de movimento não é uma propriedade específica ou idiossincrática deste tipo de predicados, mas antes a manifestação de uma característica aspetual mais genérica que seria comum a um vasto conjunto de verbos.

\section{Considerações finais}

No momento de concluir, retomamos os objetivos centrais deste estudo, no sentido de clarificar que verbos de movimento aceitam a alternância entre leituras estativas e eventivas e que fatores linguísticos lhe subjazem. A partir da distinção aspetual entre estados e eventos com verbos de movimento, consideramos vários fatores passíveis de contribuir para esta alternância, já enunciados em trabalhos anteriores, como o movimento "fictício", os tempos gramaticais e os tipos de Sujeito. Tendo concluído que nenhum destes fatores é suficiente para dar conta desta alternância, testámos a hipótese das subclasses de verbos de movimento, concentrando a nossa atenção sobre os verbos de movimento inerentemente direcionado e os verbos de modo de movimento, procurando verificar que subclasses de verbos lhe são sensíveis. A análise dos resultados mostrou que ambas as subclasses podem ocorrer com leituras estativas e leituras eventivas, embora as primeiras se associem mais facilmente a verbos de movimento inerentemente direcionado do que a verbos de modo de movimento. Além disso, permitiu constatar que uma análise desta alternância aspetual apresenta alguns problemas, o que também se verificou relativamente aos outros fatores linguísticos avaliados.

Tendo em conta este percurso, concluímos, ainda que provisoriamente, que a propriedade da dinamicidade parece desempenhar uma função central nesta alternância entre leituras estativas e leituras eventivas, já que se afigura a característica semântica mais adequada para dar conta das restrições combinatórias observadas, e que as propriedades lexicais dos verbos em análise desempenham um papel importante no que se refere à sua legitimação ou bloqueio. A análise sistemática e aprofundada destas propriedades é a próxima etapa na continuação deste projeto de investigação. ${ }^{10}$

\footnotetext{
${ }^{10}$ Agradecemos a um revisor anónimo os comentários e observações, que contribuíram para a melhoria deste texto.
} 


\section{Referências}

Binnick, R. I. (1991) Time and the Verb. A Guide to Tense and Aspect. New York: Oxford University Press

Blomberg J. \& Zlatev J. (2014) Actual and non-actual motion: why experimentalist semantics needs phenomenology (and vice versa). Phenomenology and the Cognitive Sciences, 13(3), pp. 395-418.

Bosque, I. (2015) Inner and Outer Prepositions with Spanish Verbs of Vertical Movement. In: E. Barrajón et al. (Eds.). Verb Classes and Lexical Aspect. Amsterdam: John Benjamins, pp. 78-97.

Cunha, L.F. (2004) Semântica das Predicações estativas. Para uma Caracterização Aspectual dos Estados. Dissertação de doutoramento, Universidade do Porto.

Cunha, L.F.; Silva, F. \& Leal, A. "Leituras estativas de verbos de movimento em PE". Workshop Verbos e Preposições (Universidade do Porto, 5/5/2017).

Cunha, L.F.; Leal, A. \& Silva, F. (2018) Leituras estativas e eventivas com verbos de movimento: alguns fatores de alternância. In. Oliveira, Fátima; Leal, António; Silva, Fátima \& Silvano, Purificação (Eds.). Para Óscar Lopes: Estudos de Linguística. Porto: Afrontamento (no prelo).

Dowty, D. (1979) Word meaning and Montague grammar. Dordrecht: Reidel.

Gawron, J.M. (2007) Paths and the Language of Change. San Diego State University, San Diego, CA. [disponível on-line]

Gawron, J.M. (2009) The lexical semantics of extent verbs. San Diego State University, San Diego, CA. [disponível on-line]

Iwata, S. (1996) Motion and extent: two sides of the same coin. Studia Linguistica 50 (3), pp. 256-282.

Jackendoff, R. (1990) Semantic Structures. Cambridge, MA.: MIT Press.

Kamp, H.; Rohrer, C. (1983) Tense in texts. In: R. Bauerle; C. Schwarze; A. von Stechow (Eds.). Meaning, use and interpretation of language. Berlin: Walter de Gruyter, pp. 250-269.

Kamp, H,; Reyle, U. (1993) From Discourse to Logic: Introduction to Modeltheoretic Semantics of Natural Language, Formal Logic and Discourse Representation Theory. Dordrecht: Kluwer Academic Publishers.

Langacker R.W. (1986) Abstract motion. In Nikiforidou V., Van Clay M., Niepokuj M. \& Feder D., Proceedings of the 12th Annual Meeting of the Berkeley Linguistics Society. Berkeley, CA: Berkeley Linguistics Society, pp. 455-471.

Leal, A.; Cunha, L.F. \& Silva, F. (2018) Stative and eventive alternations with some spatial verbs. In: Leal, A. (ed.). Verbs, movement and prepositions. Porto: FLUP/CLUP.

Levin, B. (1993) English verb classes and alternations: a preliminary investigation. Chicago (IL), The University of Chicago Press.

Matlock, T. (2004) The conceptual motivation of fictive motion. In G. Radden \& R. Dirven (Eds.), Motivation in grammar (pp. 221-248). Amsterdam: John Benjamins.

Matsumoto, Y. (1996) Subjective motion and English and Japanese verbs. Cognitive Linguistics 7-2, pp. 183226.

Moens, M. (1987) Tense, Aspect and Temporal Reference. Tese de Doutoramento, Universidade de Edimburgo.

Morimoto, Y. (2013) Cuando los estados se convierten en eventos y viceversa: ¿recategorización o ambigüedad aspectual? In: A. Cabedo Nebot; M.J. Aguilar Ruiz; E. López-Navarro Vidal (Eds.) Estudios de lingüística: investigaciones, propuestas y aplicaciones. Valência: Universidade de Valência, pp. 369-377 [disponível on-line]

Morimoto, Y. (2018) Stative/eventive alternations in Spanish. In: Leal, A. (ed.). Verbs, movement and prepositions. Porto: CLUP/FLUP, pp. 45-74.

Mourelatos, A. (1981) Events, Processes and States. In: Tedeschi, P.J., and Zaenen, A. (eds.). Tense and Aspect. Academic Press: New York, NY, pp. 191-212. 
Oliveira, F.; Lopes, A. (1995) Tense and Aspect in Portuguese. In: R. Thieroff (Org.). Tense System in European Languages, vol.II. Tubinga: Max Niemeyer Verlag, 95-115.

Smith, C. 1991. The Parameter of Aspect. Dordrecht: Kluwer. [2. edição, 1997]

Rojo, A.; Valenzuela, J. (2003) Fictive motion in English and Spanish. International Journal of English Studies, 3-2, pp.123-149.

Talmy, L. (1996) Fictive motion in language and 'ception'. In: P. Bloom; M.A. Peterson; L. Nadel; M. F. Garrett (Eds.). Language and Space. Cambridge, MA.: MIT Press, pp. 211-276.

Talmy, L. (2000) Toward a Cognitive Semantics, Cambridge, MA.: MIT Press.

Vendler, Z., (1967) Linguistics in Philosophy. New York, Cornell University Press.

CETEMPúblico (Corpus de Extractos de Textos Electrónicos MCT/Público) - http://www.linguateca.pt/ 